NOTES

\title{
X-Ray Photoelectron Spectroscopy of Electron-Acceptor Doped Poly(p-phenylene sulfide)
}

\author{
Research Institute for Polymers and Textiles, \\ 1-1-4 Higashi, Yatabe-machi, Tsukuba-gun, \\ Ibaraki 305, Japan
}

Hiroshi SHIMIzU, Yoshikazu TANABE, and Hisaaki KANETSUNA

(Received July 12, 1985)

KEY WORDS XPS / Poly(p-phenylene sulfide) / Conductive Polymer / Doping Mechanism/

Considerable attention has been paid to a variety of conductive polymers such as polyacetylene, $\operatorname{poly}(p$-phenylene), polypyrrole, and polythiophene in connection with practical applications and theoretical interests in conduction mechanisms. Compared with the above-mentioned conjugated polymers, poly( $p$-phenylene sulfide) (PPS) is a non-conjugated polymer and has a characteristics of the processibility. Frommer et al. have reported a remarkably high conductivity, $200 \mathrm{~S} \mathrm{~cm}^{-1}$, for $\mathrm{AsF}_{5}$-doped PPS film cast from $\mathrm{AsF}_{3}$ solution. ${ }^{1}$ For the conduction mechanism of $\mathrm{AsF}_{5}$-doped PPS, several ideas such as the formation of benzothiophene structure ${ }^{2}$ and intermolecular crosslinking ${ }^{3}$ have been proposed from the results of elementary analysis and IR spectral measurements. However, it is necessary to obtain more detailed information on the doping mechanism of electron-acceptor doped PPS in order to discuss the conduction mechanism. Recently we have reported the existence of the two conduction mechanisms in $\mathrm{SO}_{3}$ or $\mathrm{SbF}_{5}$ doped PPS from optical absorption measurements. ${ }^{4}$ At lower doping levels, bipolaron states exist and these are unstable in the atomosphere. At higher doping levels, other conduction mechanism appears which is stable in the atmosphere.
Only the latter conduction mechanism exists in the atmosphere.

In this note we measured XPS (X-ray photoelectron spectroscopy) spectra of PPS films heavily doped with electron acceptors: these films have only the stable conduction mechanism. From XPS spectra the doping mechanism, of these films is discussed, which depends on dopants. XPS is useful for the investigation of charge-transfer complexes and organic ions. ${ }^{5-7}$

\section{EXPERIMENTAL}

Thin transparent films of PPS $(15-25 \mu \mathrm{m}$ thick) were offered from Kureha Chemical Industry Co., Ltd. PPS films were doped with electron acceptors such as $\mathrm{SbF}_{5}, \mathrm{SO}_{3}$, and $\mathrm{I}_{2}$ in the vapor phase under a pressure of $c a .4$ torr. XPS spectra were measured using Shimadzu Electron Spectrometer ESCA 750. The binding energies $E_{\mathrm{b}}$ (defined as differences between the Fermi level and the atomic level energies) are given by the equation

$$
E_{\mathrm{b}}=E_{\mathrm{h} v}-E_{\mathrm{k}}-\Phi_{\mathrm{s}}
$$

where $E_{\mathrm{h} v}$ is the energy $(1253 \mathrm{eV})$ of the X-ray excitation ( $\mathrm{Mg}-K_{\alpha}$ radiation), $E_{\mathrm{k}}$ is the measured kinetic energy of the photoejected elec- 


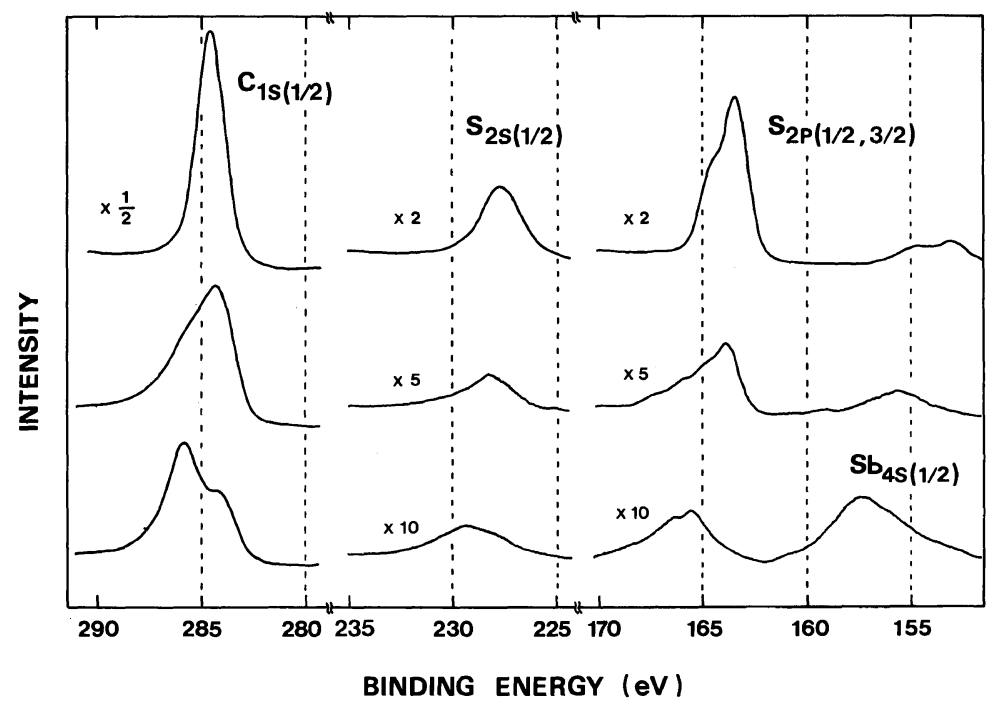

Figure 1. XPS core level spectra of undoped PPS (top) and $\mathrm{SbF}_{5}$-doped PPS (middle and bottom). The dopant concentrations of the middle and bottom curves are about $50 \mathrm{~mol} \%$ and about $150 \mathrm{~mol} \%$, respectively.

tron and $\Phi_{\mathrm{s}}$ is the spectrometer work function (the energy necessary to bring the electron from the Fermi level to the free-electron level). All measurements of XPS were performed under a pressure of about $1 \times 10^{-7}$ torr. The binding energies were calibrated by the peak position of $\mathrm{Au}_{4 \mathrm{f}(7 / 2)}$ band. All spectra were measured after the conductivity of doped-PPS reached the steady value in the atmosphere.

\section{RESULTS AND DISCUSSION}

After heavy doping of $\mathrm{SbF}_{5}$ and $\mathrm{SO}_{3}$, electrical conductivities of PPS films reached $10^{-2}$ and $10^{-5} \mathrm{~S} \mathrm{~cm}^{-1}$, respectively. Though the conductivity of these films decreased by a factor of $c a .10^{3}$ after exposing to the atmosphere, reduced ones were relatively stable in the atmosphere for a long time (one month or so). In case of PPS doped with $\mathrm{I}_{2}$, the conductivity was lower than $10^{-12} \mathrm{~S} \mathrm{~cm}^{-1}$. These differences of conductivities reflect the various doped states.

\section{1) $\mathrm{SbF}_{5}$-Doped PPS}

Figure 1 shows XPS spectra of undoped (top) and $\mathrm{SbF}_{5}$-doped PPS film (middle and bottom). The middle spectra of Figure 1 correspond to the films in which dopant concentration is about $50 \mathrm{~mol} \%$ (conductivity is about $10^{-9} \mathrm{~S} \mathrm{~cm}^{-1}$ ) and the bottom ones correspond to those doped with about $150 \mathrm{~mol} \%$ $\mathrm{SbF}_{5}$ (as high as $10^{-7} \mathrm{~S} \mathrm{~cm}^{-1}$ ). Undoped PPS film has three bands at 284.5, 227.8, and 163.5 (164.5) eV, which were assigned to carbon $1 \mathrm{~s}$ $\left(\mathrm{C}_{1 \mathrm{~s}}\right)$, sulfur $2 \mathrm{~s}\left(\mathrm{~S}_{2 \mathrm{~s}}\right)$, and sulfur $2 \mathrm{p}\left(\mathrm{S}_{2 \mathrm{p}}\right)[1 / 2$, $3 / 2$ spin] electrons, respectively. The $C_{1 \mathrm{~s}}$ band corresponds to carbon atoms of phenyl rings in PPS, while $S_{2 s}$ and $S_{2 p}$ bands are attributed to the divalent sulfur atoms. The $S_{2 p}$ band of undoped PPS exhibits satellite peaks at 155 and $153 \mathrm{eV}$. As shown in middle and bottom curves of Figure 1, XPS spectra of $\mathrm{SbF}_{5}$-doped PPS changed in binding energy, in band intensity, and in band shape with doping. These spectral changes were correlated with the band intensity of $\mathrm{Sb}_{4 \mathrm{~s}}$ (observed at $157.5 \mathrm{eV}$ ) which was related to the doping level of $\mathrm{SbF}_{5}$. When the band intensity of $\mathrm{Sb}_{4 \mathrm{~s}}$ was relatively small, 
very broad $\mathrm{C}_{1 \mathrm{~s}}$ and $\mathrm{S}_{2 \mathrm{p}}$ bands with pronounced shoulder on the side of higher binding energy were observed (middle of Figure 1).

As shown in the bottom curves of Figure 1, the $\mathrm{C}_{1 \mathrm{~s}}$ spectrum of $\mathrm{SbF}_{5}$-doped PPS exhibited two distinct carbon $1 \mathrm{~s}$ electron lines (284.5 and $286 \mathrm{eV}$ ) with relative separation of $1.5 \mathrm{eV}$. The peak with higher binding energy suggests the formation of cationic species, ${ }^{5,6}$ where positive charges are delocalized over the corresponding

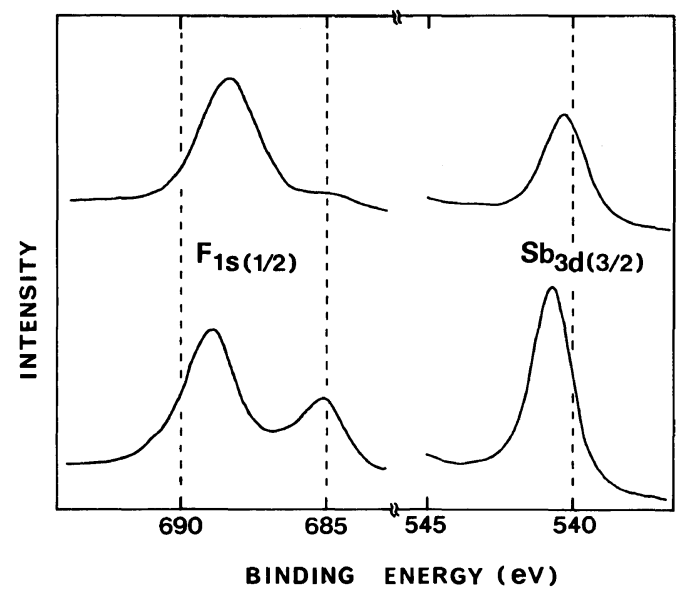

Figure 2. $\mathrm{F}_{1 \mathrm{~s}(1 / 2)}$ and $\mathrm{Sb}_{3 \mathrm{~d}(3 / 2)}$ XPS core level spectra of $\mathrm{SbF}_{5}$-doped PPS, in which the same samples were used as ones shown in Figure 1. The upper and lower spectra correspond to the middle and bottom curves of Figure 1, respectively. phenyl rings. In the case of $S_{2 s}$ and $S_{2 p}$ XPS bands of PPS heavily doped with $\mathrm{SbF}_{5}$, only peaks with higher binding energy were observed at 229.5 and $165.5 \mathrm{eV}$, respectively. The chemical shift of $S_{2 \mathrm{~s}}$ and $S_{2 p}$ electrons (1.7 and $2.0 \mathrm{eV}$ respectively) also suggests the localized positive charges on sulfur atoms ${ }^{8,9}$ resulting in the formation of the divalent and/or trivalent sulfur cations.

Figure 2 shows the XPS spectra of the dopant, $\mathrm{F}_{1 \mathrm{~s}(1 / 2)}$ and $\mathrm{Sb}_{3 \mathrm{~d}(3 / 2)}$ electrons in $\mathrm{SbF}_{5}$ doped PPS films. In this figure, the same samples were used as ones shown in Figure 1. Hence, the doping levels of the upper and lower spectra are same as the middle and bottom curves of Figure 1, respectively. As shown in lower curve of Figure 2, the two distinct $F_{1 \mathrm{~s}}$ bands separated by $3.9 \mathrm{eV}$ were observed, and the peak position of $\mathrm{Sb}_{3 \mathrm{~d}}$ slightly shifted to higher binding energy $(0.4 \mathrm{eV})$ compared to that of upper line. In the two $F_{1 \mathrm{~s}}$ bands, the band observed at $685 \mathrm{eV}$ indicates the enhancement of anionic character of $F$ atom by the effect of charge transfer from PPS chain. The chemical shift of $\mathrm{Sb}_{3 \mathrm{~d}(3 / 2)}$ band would denote the increase in covalence of $\mathrm{Sb}$ atoms.

These results (Figures 1 and 2) clearly suggest the formation of charge-transfer structure

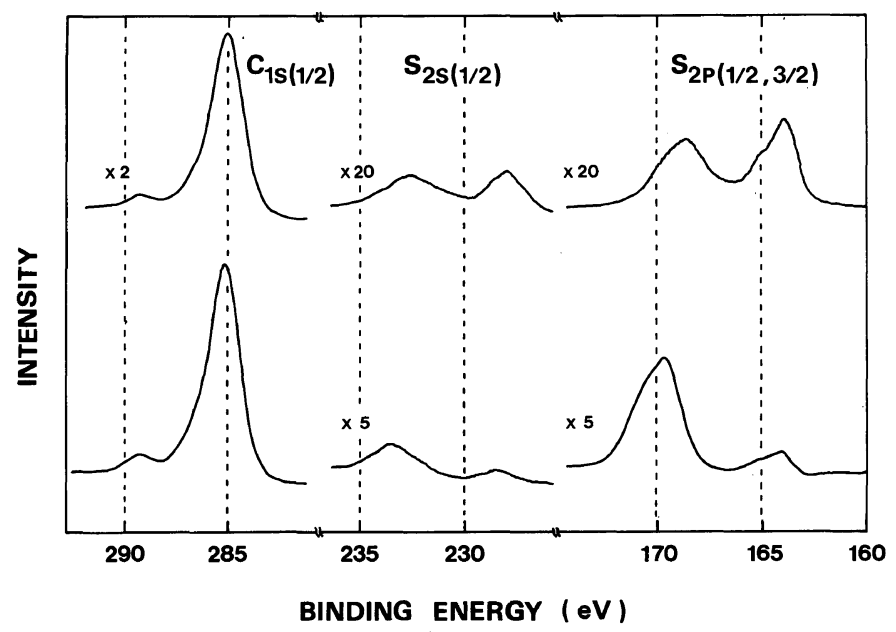

Figure 3. XPS core level spectra of $\mathrm{SO}_{3}$-doped PPS. The concentrations of $\mathrm{SO}_{3}$ are about $60 \mathrm{~mol} \%$ (upper curves) and about $200 \mathrm{~mol} \%$ (lower curves). 
such as $(\mathrm{PPS})^{+}\left(\mathrm{SbF}_{6}\right)^{-}$for the $\mathrm{SbF}_{5}$-doped PPS films.

\section{2) $\mathrm{SO}_{3}$-Doped $\mathrm{PPS}$}

The XPS spectra of $\mathrm{SO}_{3}$-doped PPS are shown in Figure 3. The concentrations of $\mathrm{SO}_{3}$ are about $60 \mathrm{~mol} \%$ for the upper spectra and about $200 \mathrm{~mol} \%$ for the lower spectra. In these spectra (especially lower curves), a new $S_{2 p}$ band with the separation of $6 \mathrm{eV}$ from the original band of undoped PPS (see Figure 1) was observed at $169.5 \mathrm{eV}$. The $\mathrm{S}_{2 \mathrm{~s}}$ spectrum showed also the new band (5.7 eV higher than that of undoped one). From the comparison of these spectra with those of polyethersulfone, phenyl $p$-toluenesulfonate, and sodium $p$ styrenesulfonate, the new bands were assigned to the hexavalent sulfur atom resulting in the formation of sulfone and/or sulfonate.

The chemical shifts of $\mathrm{S}_{2 \mathrm{~s}}(228.5 \mathrm{eV})$ and $\mathrm{S}_{2 \mathrm{p}}$ $(164 \mathrm{eV})$ bands were 0.7 and $0.5 \mathrm{eV}$ respectively, which shift to higher binding energy. The chemical shift of $\mathrm{C}_{1 \mathrm{~s}}$ line was $0.5 \mathrm{eV}$. These results suggest that weak charge-transfer structure is also formed in this PPS- $\mathrm{SO}_{3}$ system.

The small $\mathrm{C}_{1 \mathrm{~s}}$ band at $289.2 \mathrm{eV}$ would reflect the presence of the sulfonate resulting in the formation of the interchain crosslinking rather than presence of the trivalent carbocation.

From the above-mentioned results, the doping of $\mathrm{SO}_{3}$ seems to mainly induce the sulfonation on PPS chain, although chargetransfer structure appears weakly.

\section{3) $I_{2}$-Doped PPS}

The $\mathrm{C}_{1 \mathrm{~s}}, \mathrm{~S}_{2 \mathrm{~s}}$, and $\mathrm{S}_{2 \mathrm{p}}$ spectra of PPS were little affected by the doping of $\mathrm{I}_{2}$, while the complicating XPS bands of $\mathrm{I}_{3 \mathrm{~d}(3 / 2)}$ and $\mathrm{I}_{3 \mathrm{~d}(5 / 2)}$ were observed. This means that iodine hardly contributes to form the charge-transfer structure in PPS chain.
In conclusion, the XPS spectra of doped PPS are different each other depending on the dopant species. These results reflect the different doping mechanisms, the formation of charge-transfer structure (for $\mathrm{SbF}_{5}$ ), the occurrence of side reaction (for $\mathrm{SO}_{3}$ ) and so on. Since the PPS films doped with $\mathrm{SbF}_{5}$ have the highest conductivity in the atmosphere among our samples, charge-transfer structure seems to be important for increasing the conductivity in stable state.

Acknowledgments. Thanks are due to Dr. N. Maruyama (Kureha Chemical Industry Co., Ltd.) for kind supplying the transparent PPS films.

\section{REFERENCES}

1. J. E. Frommer, R. L. Elsenbaumer, and R. R Chance, American Chemical Society Symposium Series No. 242, p 447, Washington, 1984.

2. L. W. Shacklette, R. L. Elsenbaumer, R. R. Chance, H. Eckhardt, J. E. Frommer, and R. H. Baughman, J. Chem. Phys., 75, 1919 (1981).

3. T. C. Clarke, K. K. Kanazawa, V. Y. Lee, J. F. Rabolt, J. R. Reynolds, and G. B. Street, J. Polym. Sci., Polym. Phys. Ed., 20, 117 (1982).

4. Y. Tanabe, H. Shimizu, and H. Kanetsuna, Rep. Prog. Polym. Phys. Jpn., 28, 381 (1985).

5. G. A. Olah, G. D. Mateescu, L. A. Wilson, and M. H. Gross, J. Am. Chem. Soc., 92, 7231 (1970).

6. G. A. Olah, G. D. Mateescu, and J. L. Riemenschneider, J. Am. Chem. Soc., 94, 2529 (1972).

7. G. D. Mateescu, J. L. Riemenschneider, J. J. Svoboda, and G. A. Olah, J. Am. Chem. Soc., 94, 7191 (1972).

8. A. Fahlman, K. Hamrin, J. Hedman, R. Nordberg, C. Nordling, and K. Siegbahn, Nature, 210, 4 (1966).

9. K. Siegbahn, C. Nordling, A. Fahlman, R. Nordling, K. Hamrin, J. Hedman, G. Johansson, T. Bergmark, S.-E. Karlsson, I. Lindgren, and B. Lindberg, "ESCA, Atomic, Molecular and Solid State Structure Studied by Means of Electron Spectroscopy," Almqvist and Wiksells Boktryckeri Ab, Uppsala, 1967, p 125 and 139. 